\title{
Plasma nitrite concentrations decrease after hyperoxia-induced oxidative stress in healthy humans
}

\author{
Darko Modun ${ }^{1 *}$, Mladen Krnić ${ }^{2}$, Jonatan Vuković ${ }^{1}$, Višnja Kokić ${ }^{1}$, Lea Kukoč-Modun ${ }^{3}$, Dimitrios Tsikas ${ }^{4}$, Zeljko Dujić ${ }^{5}$ \\ From 18th Scientific Symposium of the Austrian Pharmacological Society (APHAR). Joint meeting with the \\ Croatian, Serbian and Slovenian Pharmacological Societies. \\ Graz, Austria. 20-21 September 2012
}

\section{Background}

We measured plasma nitrite, the biochemical marker of endothelial nitric oxide ( $\left.{ }^{\circ} \mathrm{NO}\right)$ synthesis, before and after hyperoxia, in order to test the hypothesis that hyperoxiainduced vasoconstriction is a consequence of reduced bioavailability of ${ }^{\circ} \mathrm{NO}$ due to elevated oxidative stress.

\section{Methods}

Ten healthy males breathed $100 \%$ normobaric $\mathrm{O}_{2}$ for 30 min between the $15^{\text {th }}$ and $45^{\text {th }}$ min of the 1 h study protocol. Plasma nitrite and malondialdehyde (MDA), arterial stiffness (indicated by augmentation index, AIx) and arterial oxygen $\left(\mathrm{P}_{\mathrm{tc}} \mathrm{O}_{2}\right)$ pressure were measured in the $1^{\text {st }}, 15^{\text {th }}, 45^{\text {th }}$ and $60^{\text {th }}$ minute of the study.

\section{Results}

Breathing of normobaric 100\% oxygen during $30 \mathrm{~min}$ caused an increase of $\mathrm{P}_{\mathrm{tc}} \mathrm{O}_{2}$ (from $75 \pm 2$ to $412 \pm 25 \mathrm{~mm}$ $\mathrm{Hg}$ ), AIx (from $-63 \pm 4$ to $-51 \pm 3 \%$ ) and MDA (from $152 \pm 13$ to $218 \pm 15 \mathrm{nmol} / \mathrm{L}$ ) and a decrease in plasma nitrite (from $918 \pm 58$ to $773 \pm 55 \mathrm{nmol} / \mathrm{L}$ ). During the 15-min recovery phase the plasma nitrite, AIx and MDA values remained altered.

\section{Conclusions}

This study suggests that the underlying mechanism of hyperoxia-induced vasoconstriction may result from reduced 'NO bioavailability due to elevated and sustained oxidative stress.

\footnotetext{
* Correspondence: darko.modun@mefst.hr

'Department of Pharmacology, School of Medicine, University of Split, 21000 Split, Croatia

Full list of author information is available at the end of the article
}

\section{Author details}

'Department of Pharmacology, School of Medicine, University of Split, 21000 Split, Croatia. ${ }^{2}$ Department of Endocrinology, University Hospital Split, 21000 Split, Croatia. ${ }^{3}$ Department of Analytical Chemistry, Faculty of Chemistry and Technology, University of Split, 21000 Split, Croatia. ${ }^{4}$ Institute of Clinical Pharmacology, Hannover Medical School, 30625 Hannover, Germany. ${ }^{5}$ Department of Physiology, School of Medicine, University of Split, 21000 Split, Croatia.

Published: 17 September 2012

doi:10.1186/2050-6511-13-S1-A88

Cite this article as: Modun et al:: Plasma nitrite concentrations decrease after hyperoxia-induced oxidative stress in healthy humans. $B M C$

Pharmacology and Toxicology 2012 13(Suppl 1):A88.
Submit your next manuscript to BioMed Central and take full advantage of:

- Convenient online submission

- Thorough peer review

- No space constraints or color figure charges

- Immediate publication on acceptance

- Inclusion in PubMed, CAS, Scopus and Google Scholar

- Research which is freely available for redistribution
C Biomed Central

\section{Biomed Central}

